\title{
Theory of Arts and Humanities Courses on College Students' Humanities Accomplishment Promotion Effect
}

\author{
Hongxiang Zhao \\ School of Economics and Management, Shenyang Aerospace University, Shenyang, China
}

Keywords: Course of Arts and Humanities; Humanistic Quality; College

\begin{abstract}
The course of Humanistic quality improves the ability of using language expertly and promotes comprehensive quality in university student. In this essay, firstly, i will elaborate the specific roles of course of Arts and Humanities on improvement of humanistic quality, and then i will raise some methods that could improve humanistic quality on university students through analyzing some aspects and phenomenon of humanistic quality in recent years.
\end{abstract}

\section{Introduction}

The ability of using Chinese expertly could be improved in Arts and Humanities courses by explaining a range of classical literature. It could affect students' learning and growth.The basic reason why those are classical literature is that it conclude several of humanism idea and many skills of using language. Therefor classical literature must improve the humanistic quality of university students to a large extent.

\section{The Problems of Humanistic Quality in Modern Students}

The structure of humanistic knowledge is unbalanced. A large amount of students have a negative attitude on reading world literature and learning traditional Chinese culture, in contrast, students have a strong interest in practical exams, like computing degree exam. The reasons of causing this phenomenon are complex. For example, common "worshipful major" thought causes students pay more attention to vocation instead of academics, pragmatism of studying in students' mind and the deviation of Arts and Humanities courses' importance in teaching. Meanwhile the environment of international spread changed the way of accepting information and considering questions in students' mind, let they ignore the importance of reading classical literature.

The emotion of humanities is indifferent. A famous scholar named Qian Liqun said: "in my opinion, there are two horrible ideological trends in our Chinese university, they are pragmatism and nihilism. Pragmatism is used by individual profits, so it must trend to nihilism. Everything that expect fashion and benefits are unbelievable and could be abandoned and given up. These two ideological trends cause two results, firstly knowledge trend to vocational. It means all knowledge could be refused if it is unrelated to vocation. If teacher refuse to teach this knowledge, so do students. Secondly, the emotion is no moral. It means that refuses to any emotion aspiring and insisting." In this market-economic environment that seeking maximized benefits, the world and life outlook and values of students have been changed. Their principle of being human is full of benefits, their relationship lack of emotions. They usually show peaceful in their faces instead of hearts. Our traditional culture, like respecting elder and children and helping each other, has a similar problem to changing.

Students are confused in values and lack of responsibility. When they graduate from college and face to choose their jobs, they do not know what they want to undertake and obtain. Blundering social environment disturbs peaceful of university and original target of teaching and learning.

Arts and Humanities is a common course, it is difficult to research successfully and establish an academic essay in core monograph. In addition, there is few subject of humanities in our country, there is no subject that professor could research. Therefor a large number of lecturers in a boundary location. It causes many lecturers who teach this subject lose their confidence. More and more lecturers could not focus on teaching and realize students' thoughts. They cannot teach in a efficient 
method and students' emotions are not cultivated actually, let students lack humanistic quality likewise. In students point, they are easy to produce blundering and windy emotion with a boundary and commercialized environment of classical structure and traditional language. With the increase of pressure of employment, students are eager for quick success.

The emotion and life of students are impacted by international culture. In the one hand, the freedom of international culture makes students could communicate at random and obtain information conveniently, students also could express their views in free. On the other hand, the environment of internet provides a large number of complex information. Students whose values and life outlooks are not forming are easy to abstract by colorful images and shallow perceptual texts, they refuse to read words, especially classical literature. A report displayed by $\mathrm{Fu}$ Dan university showed that the classical literature about vocation which read by students in their free times only accounts for $15.2 \%$, whereas humanistic and scientific literature accounts for $22.8 \%$, the vocational periodicals accounts for $9.3 \%$. The students' reading quality of classical literature in USA is more than Chinese about 500 pages per week.

\section{The Improvement of Humanistic Quality}

Some students are mean when they make relationship with others. One of aspect of acquiring students need to be possessed in Arts and Humanities is considering others and social even country's benefits, meanwhile coming true self-value by helping others. Because of the popular of utilitarianism, many students have a money worship outlook. It makes many students are mean when they make a relationship with others, they only focus on their own benefits. This view is not suit for the core point that addresses to respect and take care others in Arts and Humanities; it is also different from traditional virtue of china.

Some students do not want to make progress and fear the hardness and failure. As for students in university, the change of environment has a significant influence on their outlooks. Especially, they need to face more difficult competition than in high school and prepare for enter the society. During this period, they need to understand some knowledge of arts and humanities as their motivations and adapt to the change, they should adjust themselves in this new environment and obtain a good basic for their development. However, many undergraduates are ignorant of the neglect of humanities and arts education. After a few difficulties, they have to give up on themselves. They do not realize the importance of temporary difficulties and their own efforts.

Lack of basic knowledge of the humanities accumulation. For university students, the main knowledge of their education in school is their academic knowledge, the humanities of the basic knowledge is obtained through the arts and humanities courses. In this case, because of the neglect of humanities and art courses in many college students, the lack of basic knowledge of humanities is very common.

\section{The Humanities and Arts Curriculum to Enhance the Role of Humanistic Accomplishment of College Students}

To Develop a Sense of Solidarity and Respect for the Humanistic Sense of Caring for Others. The classical literary works in the course of humanistic art education shine with the ideological light of respecting and caring for others, uniting friendship and paying attention to collective honor. Chinese traditional culture emphasizes the spirit of benevolence, as well as loyalty filial piety of virtue, are stressed on older friends and brothers. The descriptions and examples are abundant in the various Confucian classics in China. Therefore, through the humanities and art courses to teach these literary classics teaching and learning, students can absorb the essence of the corresponding ideas, and gradually develop a unity of friendship, respect for humanistic senses of others.

To Develop Self-Improvement, not Afraid of the Spirit of Difficulty. As a material of the humanities and arts curriculum in many literary works, undergraduates should have a variety of self-improvement, not afraid of the spirit of praise. Promoting college students in the study and life 
difficulties can usually keep an optimistic and uplifting spirit, students should not decadent, not to the fate of bow and perseverance, for their future success laid a good foundation.

Increasing the Accumulation of Students in the Humanities Knowledge. Any literary works are bound with a specific historical background and other human knowledge associated with human arts curriculum in a variety of literary classics, it is often the same period of history in literature and the strongest voice. The course of humanities art for college students is in fact the process of accumulating the corresponding humanities knowledge. Therefore, the study of literary works in the course of humanities and arts plays a significant role in the accumulation of humanistic knowledge of college students. In summary, the humanities and arts curriculum education can encourage students to get along with others to respect and care for others to develop good habits and to treat themselves to form self-improvement, not afraid of difficulties perseverance spirit, but also the process of learning literature could increase its focus on the teaching of human knowledge concept of literary inheritance of language academic accumulation, so as to enhance its humanistic qualities.

\section{The Concrete Measures to Enhance the Humanistic Quality of College Students in the Course of Humanistic Art}

Improving the humanistic accomplishment of teachers, and attaching importance to the cultivation of college students' humane quality in professional courses. The old saying: "body teaching is more important than words", in the process of getting along with teachers, students will observe and learn the behavior of teachers, so the teacher's behavior and its humanistic quality of the students thought and connotation of the training play an important effect. In the process of teaching, it is necessary to cultivate the students' humanistic quality. Teachers who teach professional courses should also infiltrate humanistic education into the teaching of specialized courses. In the first, we should cultivate students' first sound personality, culture, moral quality of the noble people, and then make them have the subject of professional knowledge. Therefore, the professional curriculum teachers should add the humanities education and ideological and moral education into the professional courses; so that students learn professional knowledge at the same time could be able to feel the quality of education.

Strengthening the humanities education, meanwhile handling the relationship between humanities education and professional education. A person's cultural knowledge determines a connotation, so colleges and universities should establish a complete humanistic education curriculum, the adjustment of the original curriculum. In order to give full play to the humanities the role of art course in promoting the humanistic quality of college students, only to improve the humanistic spirit of literature in the humanities and arts courses in proportion.

Classroom teaching focuses on the introduction of the corresponding background knowledge. In the course of teaching humanities and arts courses, the humanistic art teachers take on the task not only to explain the language art in the corresponding literary works adequately. Therefore, it is necessary to introduce the background knowledge in class teaching so as to give full play to its role in enhancing the humanistic accomplishment of college students.

Changing the concept of education, the establishment of a complete assessment of the quality of college students system. Nowadays, the evaluation of the quality of college students is mainly based on the quantitative means, which is completely bound by the traditional examination-oriented education and the impact of economic development and reform. The humanistic accomplishment of college students must be revealed through their behavior or ability. Therefore, university leaders should change the traditional concept of education, the implementation of people-centered quality education. Therefore, it is necessary to establish the evaluation system of humanistic accomplishment of college students. Combining the quantitative score with the qualitative index, the comprehensive evaluation of college students should be carried out, and the comprehensive quality of a student should be reflected as much as possible

Strengthening the construction of campus culture to create the atmosphere for the improvement of humanistic quality. Their own efforts to learn knowledge and a good atmosphere is an important factor in improving the humanistic quality of college students, and campus culture can reflect the 
spirit of a school in a humanistic atmosphere, the inner spirit and behavior of college students have a great impact. Universities and colleges can hold campus cultural activities by means of campus cultural festivals and reading conferences, as well as performing groups and broadcasting, so as to attract the attention of the students and participate in it so as to feel the humanistic feelings in the process of participation, appreciate, cherish and recognize this culture. Therefore, creating a strong atmosphere of the campus culture is to enhance the humanities of the effective way of college students.

To carry out multimedia teaching. With the development of science and technology, multimedia technology will be applied to their own classroom teaching, it not only enrich the classroom content and enhance teaching effectiveness. There are a large number of well-known teacher lectures exciting scenes, it also better humanities and arts curriculum to play the humanities and spirituality The unique features, so that students feel a deeper human culture.

Humanistic art curriculum should be regarded as an important carrier of humanistic education. It should point to the spiritual world of students, set up an ideal goal and model of students' ideal personality, so as to guide students to think about the purpose, meaning and value of human life. . How to realize humanities art curriculum course to cultivate humanism spirit, moral character, art quality humanism and esthetics of the student that make the human outstanding achievement and the value idea, moral standard, life attitude, aesthetic taste. So that students learn to use the truth, goodness, beauty of thinking, with a sound personality and the right vision to perceive the world, to understand life, take responsibility and heritage of our outstanding national character and national spirit. It is an important duty of every teacher of humanities and arts curriculum to be a person who is capable of doing things well. Humanities and Arts curriculum for the cultivation of the humanities has very favorable conditions for students; therefore, it needs to assume the responsibility to enhance the humanistic quality of college students. Of course, with the development of social economy, humanities education in humanistic art curriculum needs to be explored, enriched and deepened.

\section{References}

[1] T.L. Gu, X.X. Jing, Q. Guo, Y.X. Wei, A research on the training mode reform of college engineering practical talents, J. China High. Educ. Res. 1 (2012)107-110.

[2] D.N. Pan, Research on school-enterprise cooperation in tourism education in undergraduate institutions, J. Univ. Educ. 11 (2012)8-11.

[3] Q.Z. Luo, Y.Y. Xu, Exploration on school - running features of local universities - take Foshan University as an example, J. High. Educ. Forum. 5 (2009) 8-11

[4] F.F. Weng, Z.J. Liu, NCIST's schooling orientation, characteristics and internationalization strategy, J. North China Inst. Sci. Technol. 7 (2012) 118-121

[5] C.F. Ge, A Study of the construction on specialty cluster of the newly-established application oriented universities, J. High. Vocat. Educ. - J. Tianjin Vocat. Inst. 4 (2013) 48-51

[6] W.Y. Chen, Study on optimizing training program for application- oriented talents in independent colleges, J. Huazhong Agri Univ. 1 (2011) 136-139

[7] J.B. Yuan, Innovation and practice of the training mode of applied talents in independent colleges, J. Res. High. Educ. Engine. 2 (2011) 118-123

[8] P.Y. Duan, Analysis of research-oriented teaching and learning modes for cultivation of application-oriented innovative talents, J. Shangdong Jianzhu Univ. 8 (2012) 440-450. 